\title{
PEMANFAATAN YOUTUBE DALAM MENINGKATKAN KOMPETENSI TUTOR BIMBEL EDU PRIVATE
}

\author{
Krisda Lakrisida Meinawati \\ IKIP Siliwangi, Cimahi - Jawa Barat - Indonesia \\ krisdalakrisida@gmail.com
}

Received: Desember 2019 ; Accepted: Januari 2020

\begin{abstract}
This research aims to improve tutor competence Edu Private Bandung. This competency improvement is carried out through training. The training is carried out with a strategy that is carried out with the planning, implementation, and evaluation stages. Based on the identification of the problem that tutors in Edu Private Bandung tutoring are still not innovative in developing the learning media used. The lack of development of instructional media is caused by the lack of innovative tutors and from the lack of support from the institution. The media used in this training is utilizing social media Youtube. The training shows that tutors actively participate in developing learning media. The benefits of this training are to attract students 'attention so that it is easier to understand the material and attract students' attention in the learning process. The final results in this study the training process can be useful for tutors by developing more learning media, fostering student learning motivation, and making the learning atmosphere more lively. The results of this study can be used as input for tutors in other tutors including in other schools in an effort to improve tutor competence in developing learning media.
\end{abstract}

Keywords: Training, Technology Literacy.

\begin{abstract}
ABSTRAK
Penelitian ini bertujuan untuk meningkatkan kompetensi tutor bimbel Edu Private Bandung. Peningkatan kompetensi ini dilakukan meelalui pelatihan. Pelatihan dilakukan dengan strategi yang dilakukan dengan tahap perencanaan, pelaksanaan, dan evaluasi. Berdasarkan identifikasi masalah bahwa tutor di bimbel Edu Private Bandung masih belum inovatif dalam mengembangkan media pembelajaran yang digunakan. Kurangnya pengembangan media pembelajaran disebabkan oleh kurangnya inovatif tutor serta dari kurang support nya dari pihak lembaga. Media yang digunakan dalam pelatihan ini yaitu memanfaatkan media sosial Youtube. Dalam pelatihan menunjukkan bahwa para tutor berpartisipasi aktif untuk mengembangkan media pembelajaran. Manfaat pelatihan ini untuk menarik perhatian siswa agar lebih mudah memahami materi serta menarik perhatian siswa dalam proses pembelajaran. Hasil akhir dalam penelitian ini proses pelatihan dapat bermanfaat bagi tutor yaitu lebih mengembangkan media pembelajaran, menumbuhkan motivasi belajar siswa, serta membuat suasana belajar lebh hidup. Hasil dari penelitian ini dapat dijadikan sebagai bahan masukan bagi tutor di bimbel lainnya termasuk di sekolah-sekolah lainnya sebagai upaya untuk meningkatkan kompetensi tutor dalam mengembangkan media pembelajaran.
\end{abstract}

Kata Kunci: Pelatihan, Literasi Teknologi.

How to Cite: Meinawati, K.L. (2019). Pemanfaatan Youtube Dalam Meningkatkan Kompetensi Tutor Bimbel Edu Private. Comm-Edu (Community Education Journal) 3 (1), 19-26. 
20 Meinawati, K.L, Pemanfaatan Youtube Dalam Meningkatkan Kompetensi Tutor Bimbel Edu Private

\section{PENDAHULUAN}

Peraturan Menteri Pendidikan Nasional Nomor 41 tahun 2007 tentang Standar Proses penyelenggaraan pembelajaran bahwa standar proses mencangkup perencanaan proses pembelajaran, pelaksanaan proses pembelajaran, penilaian hasil pembelajaran dan pengawasan hasil pembelajaran. Pembelajaran merupakan sutau proses interaksi antara pendidik dan peserta didik. Agar proses interaksi peserta didik dengan pendidik dan sumber belajar berjalan dengan optimal dalam mencapai tujuan pembelajaran, maka kegiatan pembelajaran harus dikelola dengan baik (Wulandari, 2017)

Fungsi pendidikan nonformal sebagai suplemen atau penambah pendidikan formal di era modern ini sudah tidak asing lagi untuk ditemukan. Salah satu bentuk pendidikan nonformal sebagai penambah pendidikan formal yaitu lembaga bimbingan belajar. Lembaga bimbingan belajar merupakan salah satu lembaga pendidikan nonformal yang memberikan bimbingan berupa bimbingan belajar mengenai pelajaran akademis yang disesuaikan dengan kebutuhan peserta didik. Visi dari lembaga bimbingan belajar secara umum yaitu meningkatkan kualitas akademik atau kompetensi dari peserta didiknya. Pembelajaran yang dilakukan di lembaga bimbingan belajar sangat berbeda dengan pendidikan di sekolah pada umumnya. Adapun beberapa perbedaan yang dapat dilihat yaitu : pertama, durasi waktu pembelajaran, lembaga bimbingan belajar lebih memiliki durasi waktu yang pendek dibandingkan dengan pendidikan di sekolah. Kedua, materi pembelajaran, lembaga bimbingan belajar memberikan materi pembelajaran lebih singkat namun jelas sehingga mudah dipahami. Ketiga, kegiatan pembelajaran, pada lembaga bimbingan belajar kegiatan pembelajaran yang dilakukan biasanya dengan memberikan cara-cara cepat dalam mengerjakan soal yang semuanya tidak didapatkan di sekolah (Wulandari, 2017)

Pembelajaran tidak akan efektif jika tidak disertai dengan adanya media. Perlu adanya media agar pembelajaran semakin menarik perhatian warga belajar. Media belajar adalah alat bantu yang berguna dalam kegiatan belajar mengajar. Alat bantu dapat mewakili sesuatu yang tidak dapat disampaikan guru melalui kata-kata atau kalimat. Mempermudah kesulitan siswa memahami konsep dan prinsip tertentu dapat diatasi dengan bantuan alat bantu. Bahkan alat bantu diakui dapat melahirkan umpan balik yang baik dari anak didik. Dengan memanfaatkan taktik alat bantu yang mudah diterima (acceptable), guru dapat menggairahkan minat belajar siswa (Nugrahani, 2007)

Perubahan dunia kini tengah memasuki era revolusi industri 4.0 atau revolusi industri dunia keempat di mana teknologi informasi telah menjadi basis dalam kehidupan manusia. Perkembangan teknologi semakin cepat dan luas. Semua informasi dapat di akses dan dijangkau dengan mudah oleh siapapun. Dengan adanya teknologi banyak kemudahan yang bisa didapatkan salah satunya dengan belajar melalui media sosial tersebut.

Salah satu media sosial yang banyak diakses yaitu Youtube. Sekarang semua kalangan dapat belajar dengan menggunakan media Youtube. Ketika materi yang disampaikan di sekolah tapi belum dipahami mampu diakses kembali materinya di Youtube. Bahkan pemaparannya pun lebih mudah dimengerti, asalkan bisa memilah konten kreator yang bagus pemaparannya. Youtube merupakan media sosial no 1 penggunaanya di Indonesia, Youtube diminati oleh banyak kalangan dari yang muda hingga yang tua. Karena konten-konten di dalamnya sangat bervariatif. 
Bagi seorang pendidik yang berperan aktif dalam proses pembelajaran, pada dasarnya tutor sudah tau apa saja masalah-masalah yang ada dalam pembelajaran. Salah satu permasalahan yang ada di Bimbel Edu Private Bandung yaitu kurang inovatifnya tutor dalam mengembangkan media pembelajaran. Dalam upaya peningkatan kompetensi tutor Bimbel Edu Private Bandung, maka perlu dilakukan dengan memberikan pelatihan pengembangan media pembelajaran dengan memanfaatkan media sosial youtube. pelatihan merupakan proses pembelajaran dalam jangka waktu singkat yang diberikan untuk meningkakan keterampilan dan pengetahuan. Diharapkan dengan pelatihan ini membuat tutor lebih inovatif dalam mengembangkan media pembelajaran.

\section{LANDASAN TEORI}

\section{Media Belajar}

Terdapat beberapa definisi mengenai media pembelajaran, diantaranya adalah ada pendapat yang menyebutkan bahwa media pembelajaran merupakan alat bantu mengajar untuk menyampaikan materi agar pesan lebih mudah diterima dan menjadikan peserta didik lebih termotivasi dan aktif (Irwandani \& Juriah, 2016).

Media sumber belajar adalah alat bantu yang berguna dalam kegiatan belajar mengajar. Alat bantu dapat mewakili sesuatu yang tidak dapat disampaikan guru melalui kata-kata atau kalimat (Nugrahani, 2007).

Media pembelajaran merupakan segala sesuatu yang dapat menyalurkan pesan, dapat merangsang fikiran, perasaan, dan kemauan peserta didik sehingga dapat mendorong terciptanya proses belajar pada diri siswa dan sebagai sarana untuk mempermudah siswa dalam memahami materi yang diberikan sehingga dengan media pembelajaran diharapkan proses belajar mengajar dapat berjalan lebih baik dan hasil belajar siswa dapat meningkat. (Amalia, Ambarsari, \& Wiyogo, 2014)

Dari beberapa pendapat diatas, dapat disimpulkan bahwa media pembelajaran adalah alat bantu yang digunakan saat kegiatan belajar agar pesan dengan mudah dipahami dan dapat mendorong proses belajar pada diri siswa.

\section{Pelatihan}

Pelatihan merupakan suatu bentuk bantuan dalam proses pembelajaran yang terorganisir dan sistematis dengan jangka waktu yang relatif singkat untuk meningkatkan pengetahuan dan keterampilan peserta pelatihan yang sifatnya praktis guna mencapai tujuan tertentu. (Sugandhi, 2016).

Menurut Kamus Istilah Manajemen (1994) dalam Hidayatulloh (2019), pelatihan adalah bimbingan yang diberikan oleh instruktur untuk meningkatkan keterampilan dan pengetahuan melalui penyelesaian tugas dan latihan.

Berdasarkan pendapat diatas, dapat disimpulkan bahwa pelatihan merupakan proses pembelajaran dalam jangka waktu singkat yang diberikan untuk meningkakan keterampilan dan pengetahuan. 
22 Meinawati, K.L, Pemanfaatan Youtube Dalam Meningkatkan Kompetensi Tutor Bimbel

Edu Private

\section{Literasi Teknologi}

Literasi teknologi adalah kemampuan untuk menggunakan, memahami, mengatur, dan menilai suatu inovasi yang melibatkan proses dan ilmu pengetahuan untuk memecahkan masalah dan memperluas kemampuan seseorang. National Academy of Engineering and National Research Council of The National Academies mendefisinikan literasi teknologi sebagai sebuah pemahaman tentang teknologi pada sebuah tingkatan yang memungkinkan pemanfaatan secara efektif dalam masyarakat teknologi (Nasution, 2018).

ICT literacy itu pada dasarnya merupakan kemampuan yang dimiliki seseorang menyangkut dua hal yang meliputi kemampuan teknik (technical literacy) dan kemampuan informasi (information literacy) dalam kaitan keperluannya untuk melakukan aktifitas komunikasi dan informasi melalui medium computer (Imran, 2010).

Jadi, dapat disimpulkan bahwa literasi teknologi adalah memahami, menggunakan dan kemampuan yang dimiliki seseorang menyangkut teknologi dan informasi dalam memperluas kemampuan seseoran untuk memecahkan masalah.

\section{METODE PENELITIAN}

Dalam penelitian ini peneliti menggunakan metode penelitian kualitatif sehingga pendekatan yang digunakan adalah pendekatan deskriptif kualitatif dan akan menghasilkan data deskriptif berupa kata-kata tertulis atau lisan dari orang-orang dan perilaku yang diamati. yang bertujuan untuk menggambarkan upaya yang dilakukan oleh tutor dalam meningkatkan kompetensi untuk mengembangkan media pembelajaran yang ada di aplikasi Youtube. Menurut (Sugiyono, 2014) metode penelitian kualitatif adalah metode penelitian yang berlandaskan pada filsafat postpositivisme, digunakan untuk meneliti pada kondisi objek yang alamiah, (sebagai lawannya adalah eksperimen) dimana peneliti adalah sebagai instrumen kunci, teknik pengumpulan data dilakukan secara wawancara. Teknik pengumpulan data melalui wawancara dengan tutor bimbel Edu Private dan Siswa Edu Private sejumlah 10 orang (5 Orang tutor dan 5 orang Siswa) sebagai sampel dalam penelitian ini, dengan alasan siswa dan tutor merupakan bagian penting dalam proses pembelajaran. Lokasi penelitian ini di Jalan Papanggungan No 24, Bandung.

Metode pelaksanaan penelitian pada tutor terbagi dalam tiga tahap yaitu: (1) tahap perencanaan, (2) tahap pelaksanaan, (3) tahap evaluasi. Tahap perencanaan telah ditetapkan hal-hal sebagai berikut: tempat/lokasi kegiatan dipilih di Bimbel Edu Private Bandung. Jenis kegiatan berupa pengembangan media pembelajran melalui konten media sosial Youtube. Kegiatan pengembangan media pembelajaran di Bimbel Edu Private terdiri atas beberapa tahapan sebagai berikut: perijinan ke owner Edu Private Bandung; Wawancara dengan tutortutor Edu Private Bandung; sosialisai mengenai mpengembangan media pembelajaran; praktik dan pendampingan; evaluasi hasil kegiatan. 1. Perijininan ke owner Edu Private Bandung. Kegiatan ini bertujuan untuk menginformasikan kepada owner mengenai masalahmasalah yang ada di Bimbel Edu Private Bandung dan juga memberitahukan sasaran juga rencana kegiatan. Kegiatan ini dilakukan dengan metode diskusi langsung dengan owner Bimbel Edu Private Bandung. 2. Wawancara dengan tutor-tutor Bimbel Edu Private Bandung bertujuan untuk mengetahui media pembelajaran yang digunakan sebelum dikembangkan 3 . Sosialisasi bertujuan untuk memberikan penjelasan mengenai maksud dari penelitian ini yaitu untuk mengembangkan media pembelajaran yang digunakan. 4. Praktik dan Pendampingan 
pengembangan media pembelajaran di Bimbel Edu Private Bandung dimulai dengan menganalisis media pembelajaran yang digunakan di Edu Private Bandung, memahami media pembelajaran yang dipakai, Pelatihan media pembelajaran melalui konten media sosial Youtube, mempraktekan media pembelajaran yang dilatih melalui media sosial Youtube. 5. Evaluasi yang dilakukan dalam kegiatan ini meliputi: keaktifan, tingkat pengetahuannya, dan evaluasi keberlanjutan kegiatan.

\section{HASIL DAN PEMBAHASAN \\ Hasil}

Pertama, Pembelajaran siswa Edu private sebelum dikembangkan media pembelajaran.

Pembahasan pertama yaitu pembelajaran tutor Edu private sebelum dikembangkan media pembelajarannya yaitu menggunakan media elektronik contohnya laptop. Penggunaan laptop dengan menayangkangkan video bersama-sama dengan murid kemudian guru memberikan soal dari penayangan video tersebut. Contoh lain dengan mengkreasikan kertas-kertas. Kertas-kertas digulungkan dengan isi di dalamnya soal-soal kemudian kertas-kertas tersebut dipencar untuk dicari oleh murid ketika kertas tersebut ditemukan ada batasan waktu untuk menjawab dari gulungan kertas yang berisikan soal. Biasanya kedua media pembelajran tersebut digunakan bagi tingkatan TK dan SD.

Media pembelajaran yang digunakan sebelum dikembangkan sudah baik hanya saja itu berlaku untuk tingkatan TK dan SD. Bagi tingkatan SMP dan SMA belum dikembangkangkan media pembelajaranya sehingga kurang menarik perhatiannya, rata-rata media pembelajarannya hanya buku dan modul.

\section{Kedua, proses pelatihan pengembangan media pembelajaran kepada tutor Edu Private} melalui media sosial Youtube.

Pembahasan kedua yaitu proses pengembangan media pembelajaran. Pertama yang dilakukan yaitu sosialisasi mengenai media-media pembelajaran yang ada di konten media sosial Youtube. Kegiatan ini dilakukan dengan pelatihan agar mudah dipahami oleh tutor-tutor Edu Private. Selanjutnya dipraktekan tiap-tiap tutor Bimbel Edu Private Bandung.

Salah satu media sosial yang banyak diakses yaitu Youtube. Sekarang semua kalangan dapat belajar dengan menggunakan media Youtube. Ketika materi yang disampaikan di sekolah tapi belum dipahami mampu diakses kembali materinya di Youtube. Bahkan pemaparannya pun lebih mudah dimengerti, asalkan pintar-pintar memilih konten kreator yang bagus pemaparannya. Youtube merupakan media sosial no 1 penggunaanya di Indonesia, Youtube diminati oleh banyak kalangan dari yang muda hingga yang tua. Karena konten-konten di dalamnya sangat bervariatif.

Media pembelajaran dapat merupakan wahana penyalur pesan dan informasi belajar. Media pembelajaran yang dirancang secara baik akan sangat membantu peserta didik dalam mencerna dan memahami materi pelajaran. Di era globalisasi dan informasi ini,perkembangan media pembelajaran juga semakin maju. Penggunaan Teknologi Informasi(TI) sebagai media pembelajaran sudah merupakan suatu tuntutan.Pengembangan media pembelajrran berbasis teknologi saat ini kurang, dikarenakan masih banyak guru yang mengajar hanya bermodalkan papan tulis dan buku saja tapi tidak sedikit juga guru yang sudah menggunakan teknologi $e$-book dan juga referensi pembelajaran dari website 
24 Meinawati, K.L, Pemanfaatan Youtube Dalam Meningkatkan Kompetensi Tutor Bimbel

Edu Private

Ketiga, respon siswa Edu Private setelah pelatihan pengembangan media pembelajaran melalui media sosial Youtube.

Pembahasan ketiga yaitu respon dan hasil dari pengembangan media pembelajaran melalui konten media sosial Youtube. Hasilnya positif dari pelatihan pengembangan media pembelajaran semoga mampu diterapkan ketika sedang mengajar.

\section{Pembahasan}

Berdasarkan hasil diatas diharapkan bahwa dengan melaksanakan penelitian kompetensi guru maka akan dapat meningkatkan kompetensi guru. Model pelatihan penelitian ini prinsipnya adalah melibatkan peserta pelatihan yaitu tutor Edu Private Bandung dengan semaksimal mungkin dalam pelatihan mulai identifikasi kebutuhan, perencanaan, pelaksanaan serta terakhir evaluasi. Penggunaan model pelatihan secara kelompok maupun individual telah dapat mengatasi permasalahan kesulitan tutor dalam mengembangkan media pembelajaran. Melalui pendampingan, tutor berai mencoba dan tidak takut salah dalam mengembangkan media pembelajaran, sehingga tutor dapat mengembangkan media pembelajaran yang diimplementasikan dalam pelatihan ini.

Penelitian ini berupa pengembangan media pembelajaran bagi tutor Bimbel Edu Private Bandung. Tutor-tutor yang ada di Bimbel Edu Private Bandung merasa terbantu dan temotivasi dalam pelatihan pengembangan media pembelajaran. Dalam proses pendapingan tentunya terdapat berbagai hambatan-hambatan diantaranya sinyal internet yang kurang kuat, beberapa guru yang telat datang ketika kegiatan kegiatan. Tetapi hambatan itu bisa diatasi dan tutor-tutor memberikan hasil yang positif. Hal ini sesuai dengan pendapat (Badu, 2012) bahwa peran pelatih sebagai fasilitator yang harus memaksimalkan kinerja peserta pelatihan.

Media pembelajaran merupakan alat bantu mengajar untuk menyampaikan materi agar pesan lebih mudah diterima dan menjadikan peserta didik lebih termotivasi dan aktif (Irwandani \& Juriah, 2016) bahwa hasil penelitian menunjukkan beberapa tutor masih belum mengembangkan media pembelajaran yang digunakan. Maksud dari belum mengembangkan disini karena ada beberapa tutor yang masih menggunakan media pembelajaran hanya mengandalakan buku pelajaran dari sekolah siswanya padahal masih bisa dikembangkan agar pembelajaran semakin menarik, mudah ditangkap materi yang diberikan dan motivasi siswa semakin tinggi terhadap belajar.

Pada era ini, hanya mengandalkan buku saja terlalu membosankan maka diperlukan juga teknologi agar menimbulkan motivasi yang tinggi. Bahkan melalui internet pun bisa menemukan buku-buku yang dicari, materi materi yang dicari. Maka dari itulah diperlukan kemampuan untuk menggali informasi untuk mengembangkan media pembelajaran melalui internet salah satunya media Youtube. Menurut Imran (2010) ICT literacy itu pada dasarnya merupakan kemampuan yang dimiliki seseorang menyangkut dua hal yang meliputi kemampuan teknik (technical literacy) dan kemampuan informasi (information literacy) dalam kaitan keperluannya untuk melakukan aktifitas komunikasi dan informasi melalui medium computer.

Maka dari itu diperlukan pelatihan untuk membantu tutor dalam mengembangkan media pembelajaran. Menurut Sugandhi (2016), Pelatihan merupakan suatu bentuk bantuan dalam proses pembelajaran yang terorganisir dan sistematis dengan jangka waktu yang relatif singkat untuk meningkatkan pengetahuan dan keterampilan peserta pelatihan yang sifatnya praktis guna mencapai tujuan tertentu. Pelatihan yang dilakukan menggunakan media 
Youtube agar memudahkan para tutor karena di media Youtube sangat lengkap dan jelas karena disertakan videonya.

\section{KESIMPULAN DAN SARAN \\ Kesimpulan}

Pelatihan ini dianggap sangat penting untuk melatih tutor dalam mengatasi permasalahan siswa dalam belajar. Pelatiha ini dilakukan dalam upaya pengembangan media pembelajaran untuk menarik perhatian siswa dalam proses pembelajran serta memberikan motivasi terhadap siswa untuk belajar dan juga memberikan suasana yang hidup dalam proses pembelajaran.

Berdasarkan hasil pelaksanaan pengembangan media pembelajaran pada tutor-tutor Bimbel Edu Private Bandung, maka dapat disimpulkan hal-hal sebagai berikut:

1. Kegiatan pengembangan media pembelajaran ini bisa memberikan manfaat langsung kepada para tutor, khususnya tutor Bimbel di Edu Private Bandung dalam meningkatkan pengetahuan, keterampilan, dan kesadaran mengenai media pembelajaran.

2. Kegiatan pengembangan media pembelajaran dapat dijadikan sarana berinovasi dalam mendorong motivasi belajar siswa.

\section{Saran}

Seorang guru yang profesional perlu mengembangkan diriuntuk memenuhi tuntutan dalam tugasnya sebagai pendidik. Sebagai guru profesional salah satu alternatif untuk mengembangkan diri dengan pengembangan media pembelajaran.

\section{REFERENSI}

Amalia, R., Ambarsari, N., \& Wiyogo, M. (2014). MEMBANGUN MEDIA PEMBELAJARAN INTERAKTIF BERBASIS WEB UNTUK ANAK BERGAYA BELAJAR VISUAL TINGKAT SEKOLAH DASAR. Open Access Journal of Information Systems (OAJIS), 269-274.

Badu, A. M. (2012). Pengembangan Model Pelatihan Pendampingan dalam Rangka Peningkatan Kompetensi Pendamping Pada Kelompok Usaha Konveksi di Kota Gorontalo . Bandung: Program Pascasarjana UPI.

Hidayatulloh, H. N. (2019). IMPLEMENTASI PROGRAM PELATIHAN KOMPUTER BAGI WARGA BELAJAR PAKET C. comm edu 2(1), 59-68.

Imran, H. A. (2010). LITERASI TEKNOLOGI INFORMASI DAN KOMUNIKASI MASYARAKAT PEDESAAN . academia.edu.documents, 1-39.

Irwandani, \& Juriah, S. (2016). PENGEMBANGAN MEDIA PEMBELAJARAN BERUPA KOMIK FISIKA BERBANTUAN SOSIAL MEDIA INSTAGRAM SEBAGAI ALTERNATIF PEMBELAJARAN. Jurnal Ilmiah Pendidikan Fisika Al-BiRuNi 05 (1), 3342 . 
26 Meinawati, K.L, Pemanfaatan Youtube Dalam Meningkatkan Kompetensi Tutor Bimbel Edu Private

Nasution, S. H. (2018). PENTINGNYA LITERASI TEKNOLOGI BAGI MAHASISWA CALON GURU MATEMATIKA. Jurnal Kajian Pembelajaran Matematika 2(1), 1418.

Nugrahani, R. (2007). Media Pembelajaran Berbasis Visual Berbentuk Permainan Ular Tangga Untuk Meningkatkan Kualitas Belajar Mengajar Di Sekolah Dasar. journal.unnes.ac.id, 36.

Sufiyana, N. (2016). Pengembangan Media Pembelajaran Model Tutorial Untuk Meningkatkan Kemandirian Belajar Kelas VII Di SMP Bina Mulia Pontianak. media.neliti.com.

Sugandhi, D. F. (2016). PEMANFAATAN HASIL BELAJAR PADA PELATIHAN KETERAMPILAN MEKANIK OTOMOTIF: Studi Kasus Pada Lulusan Lembaga Pendidikan Keterampilan Pelita Massa. Repository Indonesia University of Education, 7-41.

Sugiyono. (2014). Metode Penelitian Kuantitatif Kualitatif dan $R \& D$. Bandung: Alfabeta.

Susanti, D., \& Santi. (2019). PEMANFAATAN TAMAN BACAAN MASYARAKAT (TBM) DALAM MENINGKATKAN MINAT BACA REMAJA (Studi Kasus di TBM Gunung Ilmu). jurnal comm-edu, 223-226.

Wulandari, M. (2017). MANAJEMEN PEMBELAJARAN PADA LEMBAGA BIMBINGAN BELAJAR DALAM MENINGKATKAN KOMPETENSI PESERTA DIDIK (STUDI PADA LBB KLINIK BELAJAR EDU PRIVAT DI KOTA BARU DRIYOREJO GRESIK), jurnalmahasiswa.unesa.ac.id, 2-3. 